\title{
Correction to: Disentangling the impact of nutrient load and climate changes on Baltic Sea hypoxia and eutrophication since 1850
}

\author{
H. E. M. Meier ${ }^{1,2}$ (1) K. Eilola ${ }^{2}$ - E. Almroth-Rosell ${ }^{2} \cdot$ S. Schimanke ${ }^{3} \cdot$ M. Kniebusch $^{1} \cdot$ A. Höglund $^{2} \cdot$ P. Pemberton ${ }^{2}$. \\ Y. Liu ${ }^{2} \cdot$ G. Väli ${ }^{4}$ S. Saraiva ${ }^{5}$
}

Published online: 10 October 2018

๑) Springer-Verlag GmbH Germany, part of Springer Nature 2018

\section{Correction to: Climate Dynamics \\ https://doi.org/10.1007/s00382-018-4296-y}

In Fig. 12, the data of hypoxic area from the sensitivity experiments TAIR1 (dark green solid curve) and WIND (magenta solid curve) displayed in the lower right panel were wrong. The corrected Fig. 12 is shown below.

In Sect. 3.2 (Results of the sensitivity experiments) the sentences "In REF, TAIR1, WIND and RUNOFF hypoxic areas increase considerably between the 1950s and 1970s and the temporal evolutions differ first after the 1970s slightly. In OBC, FRESH and TAIR2 and in CONST the rise in hypoxic area occurs about 5 years earlier and about 10 years later, respectively. In CONST, hypoxic area decreases again after the maximum in the 1970s." should be replaced with "In REF, TAIR1, and RUNOFF hypoxic areas increase considerably between the 1950s and 1970s and the temporal evolutions differ first after the 1970s slightly. In (1) OBC, FRESH and TAIR2 and in (2) WIND and CONST the rise in hypoxic area occurs about 5 years earlier and about 10 years later, respectively. In WIND and CONST, hypoxic area decreases again after the maximum in the 1970s."

In Table 4 the cell text for hypoxic area in TAIR "like REF" should be replaced with "smaller than REF". The corrected Table 4 is shown below.
The original article can be found online at https://doi.org/10.1007/ s00382-018-4296-y.

H. E. M. Meier

markus.meier@io-warnemuende.de

1 Department of Physical Oceanography and Instrumentation, Leibniz Institute for Baltic Sea Research Warnemünde, 18119 Rostock, Germany

2 Department of Research and Development, Swedish Meteorological and Hydrological Institute, 60176 Norrköping, Sweden

3 Climate Information and Statistics, Swedish Meteorological and Hydrological Institute, 60176 Norrköping, Sweden

4 Department of Marine Systems, Tallinn University of Technology, 12618 Tallinn, Estonia

5 Department of Mechanical Engineering, Technical University of Lisbon, 1049-001 Lisbon, Portugal 

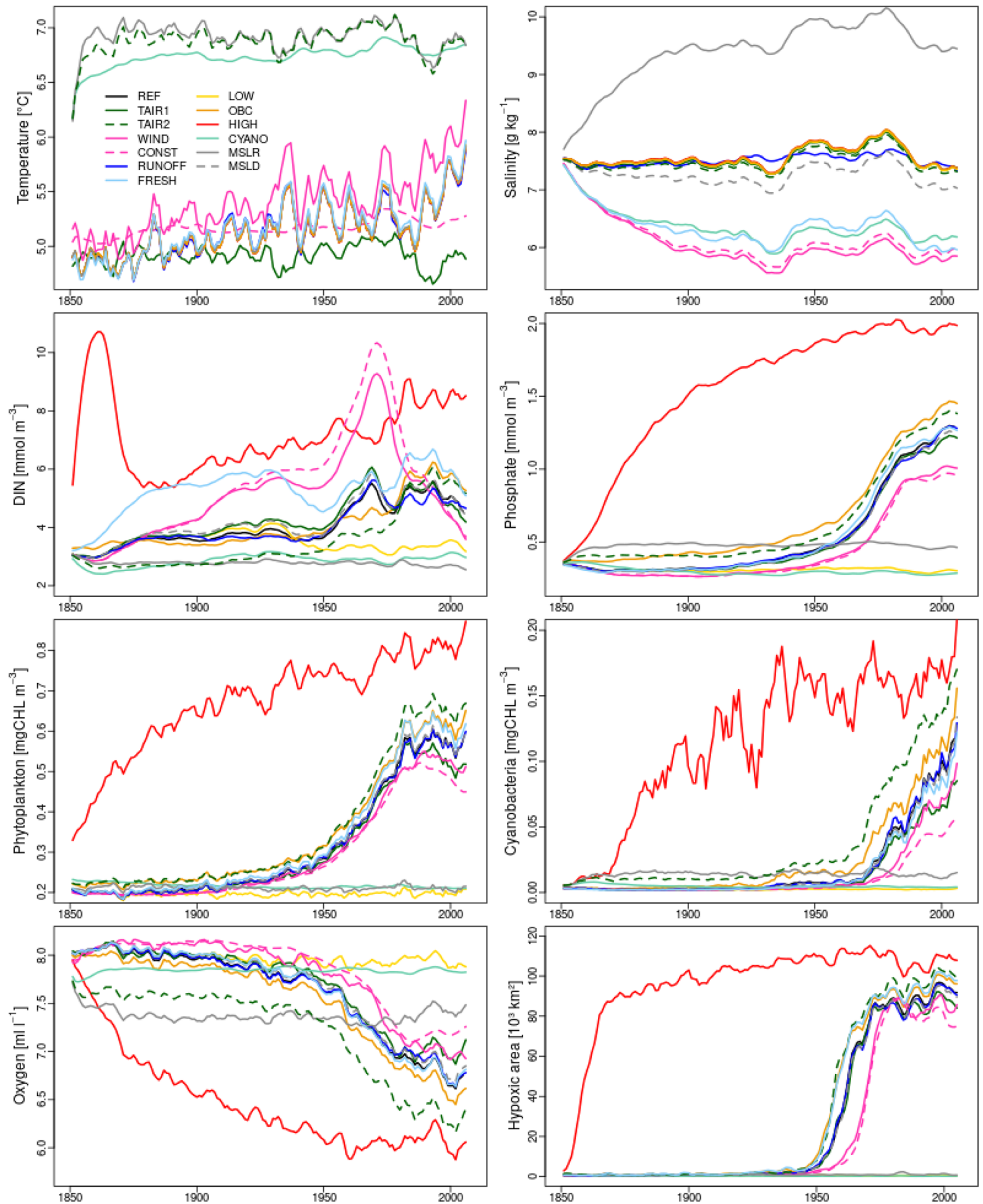

Fig. 12 4-year running mean, volume averaged annual temperature (in ${ }^{\circ} \mathrm{C}$ ), salinity (in $\mathrm{g} \mathrm{kg}^{-1}$ ), DIN (in mmol $\mathrm{N} \mathrm{m}^{-3}$ ), DIP (in

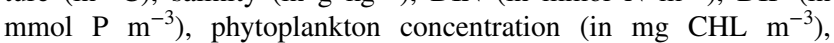
cyanobacteria concentration (in $\mathrm{mg} \mathrm{CHL} \mathrm{m}^{-3}$ ) and dissolved oxygen concentration (in $\mathrm{mL} \mathrm{O}_{2} \mathrm{~L}^{-1}$ ), and hypoxic area (in $\mathrm{km}^{2}$ ) (from upper left to lower right): REF (black solid), TAIR1 (dark green solid), TAIR2 (dark green dashed), WIND (magenta solid), CONST

(magenta dashed), RUNOFF (blue solid), FRESH (light blue solid), LOW (yellow solid), OBC (orange solid), HIGH (red solid), CYANO (turquoise solid), MSLR (gray solid), and MSLD (gray dashed). Note that the temperature curves of REF, RUNOFF, LOW, OBC, HIGH, and MSLD are on top of each other. Similarly, the salinity curves of REF, LOW, OBC, and HIGH are indistinguishable 
Table 4 Brief summary of the results of the sensitivity experiments (see Sects. 4.2, 4.3 and 4.4 of the discussion)

\begin{tabular}{|c|c|c|c|c|c|c|c|}
\hline Experiment & Temperature & Salinity & DIP & Phytoplankton & Cyanobacteria & $\begin{array}{l}\text { Oxygen concentra- } \\
\text { tion }\end{array}$ & Hypoxic area \\
\hline \multicolumn{8}{|c|}{ Removed centennial or decadal variations in hydrodynamical drivers (4.2) } \\
\hline TAIR1 & Cold & Like REF & Like REF & Lower than REF & Lower than REF & Higher than REF & Smaller than REF \\
\hline WIND & Trend & Low & Lower than REF & Lower than REF & Lower than REF & Higher than REF & Smaller than REF \\
\hline CONST & Cold & Low & Lower than REF & Lower than REF & Lower than REF & Higher than REF & Smaller than REF \\
\hline RUNOFF & Like REF & $\begin{array}{l}\text { No decadal vari- } \\
\text { ations }\end{array}$ & Like REF & Like REF & Like REF & Like REF & Like REF \\
\hline MSLD & Like REF & Slightly lower & Like REF & Like REF & Like REF & Like REF & Like REF \\
\hline \multicolumn{8}{|c|}{ Modified biogeochemical drivers on centennial time scale (4.2) } \\
\hline LOW & Like REF & Like REF & No increase & No increase & No increase & No decrease & No increase \\
\hline $\mathrm{OBC}$ & Like REF & Like REF & Higher than REF & Higher than REF & Higher than REF & Lower than REF & Larger than REF \\
\hline HIGH & Like REF & Like REF & Strong increase & Strong increase & Strong increase & Strong decrease & Large increase \\
\hline \multicolumn{8}{|c|}{ Future climate conditions (4.3) } \\
\hline TAIR2 & $+2{ }^{\circ} \mathrm{C}$ & Like REF & Higher than REF & Higher than REF & Higher than REF & Lower than REF & Larger than REF \\
\hline FRESH & Like REF & Low & Like REF & Higher than REF & Like REF & Like REF & Larger than REF \\
\hline \multicolumn{8}{|c|}{ Pristine nutrient loads (4.4) } \\
\hline CYANO & $+2{ }^{\circ} \mathrm{C}$ & Low & No increase & No increase & No increase & No decrease & No increase \\
\hline MSLR & $+2{ }^{\circ} \mathrm{C}$ & High & Slight increase & No increase & Slight increase & Higher than REF & No increase \\
\hline
\end{tabular}

